\title{
THE EFFECT OF AEROBIC EXERCISES ON PAIN, QUALITY OF LIFE IN PRIMARY HEADACHE
}

\author{
Kiruthika Selvakumar*
}

Department of Physiotherapy, Universiti Tunku Abdul Rahman, Bandar Sungai Long, Kajang, Selangor, Malaysia

Received - July 18, 2020; Revision - September 17, 2020; Accepted - October 26, 2020

Available Online - March 25, 2021

DOI: http://dx.doi.org/10.18006/2021.9(Spl-1-GCSGD_2020).S01.S09

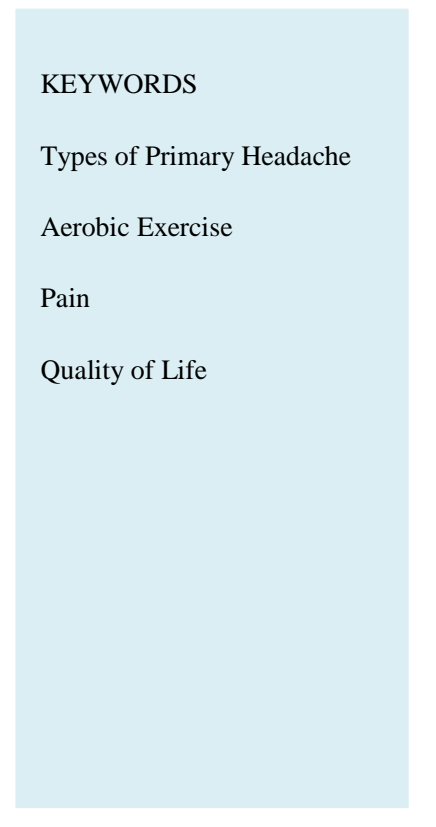

\begin{abstract}
Headache disorders are among the most common disorders of the nervous system. According to World Health Organisation reports that almost half of all adults worldwide experience a headache in any given year. Based on research, headaches are classified into primary and secondary headaches. Depending on global prevalence the most common primary headaches are migraine, tension-type, and cluster headaches. If left untreated it can result in increased pain, decreased quality of life. The objective of this literature article is to analyze the effect of aerobic exercise on pain and quality of life among subjects with primary headaches like migraine, tension-type, and cluster headache and to discuss the current updates in the literature. In this article, relevant data available in PubMed, Cochrane, and Medline databases were retrieved from 2010 to February 2020 using the search terms aerobic exercise and tension-type headaches, aerobic exercise and migraine, aerobic exercise and cluster headaches, pain, and quality of life. The search strategy identified five articles that considered the effect of aerobic exercise on primary headaches like a migraine; tension-type and cluster. Results have positive effects for aerobic exercise on tension-type headache, migraine headache mainly on pain intensity, whereas the quality of life is less studied. On the other hand, these studies did not provide a specific protocol or parameter on exercise intensities. The availability of data on the influence of aerobic exercise on primary headaches though is limited, aerobic exercises are the best option for reducing pain and improving quality of life in primary headaches, especially for tension-type and migraine-type headaches.
\end{abstract}

* Corresponding author

E-mail: kiruthika@utar.edu.my (Kiruthika Selvakumar)

Peer review under responsibility of Journal of Experimental Biology and Agricultural Sciences.

Production and Hosting by Horizon Publisher India [HPI] (http://www.horizonpublisherindia.in/).

All rights reserved.
All the articles published by Journal of Experimental Biology and Agricultural Sciencesare licensed under a Creative Commons Attribution-NonCommercial 4.0 International License Based on a work at www.jebas.org.

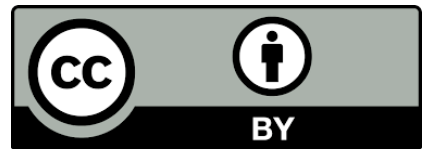




\section{Introduction}

According to World Health Organisation, headache is a disorder and most familiar problem of the nervous system. Headache is not only painful but also disabling. Headache disorders collectively ranked at third highest. It has been reported that the incidence of headache among adults is nearly half that is $47 \%$ (Jensen \& Stovner, 2008). It is estimated that half to three-quarters of adults who are aged between 18-65 years have a headache in the last year. It is approximated that $1.7-4 \%$ of the world's adult population has pain due to headaches that last for more than 15 days (Yancey et al., 2014).

Headaches are classified into primary and secondary. Secondary headaches are uncommon, but their recognition is extremely important as early intervention may be lifesaving. Primary headaches can be further classified majorly into a migraine, tension type, clusters, etc. (Carbaat \& Couturier, 2016). According to the International Classification of headache disorder, apart major subtypes include primary cough, primary exercise headache, a primary thunderclap headache, external pressure headache, primary stabbing headache, nummular headaches, hypnic headaches, etc. (Clinch, 2001).

Globally the incidence of headache disorder is still higher, with active headache around $47 \%$ for primary headache, $10 \%$ for migraine type headache, $38 \%$ tension type headache (Jensen \& Stovner, 2008). The lifetime prevalence is still more higher with $66 \%$ for headache, $14 \%$ for migraine, $46 \%$ for tension type headache, and 3-4\% for chronic headache (Stovner et al., 2007).

A cross-sectional study found 1-year prevalence and incidence of tension-type headache is $43.1 \%$, active migraine is $18.1 \%$ and the lifetime prevalence of migraine is $32.8 \%$ (Hagen et al., 2018). In cluster type headaches the incidence up to $0.1 \%$ of the population only, but it's found to be higher in females than males in the ratio of 2.5:1 (Wei et al., 2018). Cough headaches are symptomatic in about $40 \%$ and associated with secondary conditions like ArnoldChiari malformation, Vertebrobasilar disease. Primary exercise headaches are mostly of vascular origin.

Thunderclap is associated with vascular disorders and also intracranial vascular disorders. External pressure headache often results from compression or traction. Primary stabbing headache commonly associated with migraine headaches. Nummular headaches are less common. Hypnic headaches features are similar to tension-type headache, but recent studies found patient present with migraine like feature and occasionally present with nausea ("Primary Headache Disorders: Types," 2019). Hence from this prevalence it is found that migraine, tension-type and cluster headaches are the more common types.
The migraine type of pain is defined as pulsating or reverberate, and often unilateral lasting from 4 hours to a maximum of 72 hours may be associated with nausea, vomiting, sensitivity to surroundings like smell, vision, and light (Ahmed, 2012). It is found that subjects with this type of headache prefer to be in a dark, quiet room, and avoid physical activity. In tension type headaches the pain is usually aching or pressure or has a dense or rigid band around the head and this type of headache rarely affects activities of daily living.

In Cluster headaches, the pain is severe and described as a "suicidal headache". It is found to be more commonly prevalent in teenaged or adolescent men (3.5:1). The duration of pain range from 15 minutes to 3 hours and occurs from every other alternative day to up to eight days. The patient will be extremely restless and agitated and often sweats excessively (Ahmed, 2012).

The common feature of headache is pain. The causative factor for pain in primary headache is that an increase in chemical activity in the brain, blood vessels, or nerves surrounding the brain or muscles and in and around the head and neck region. DaSilva stated, "during a migraine attack, the patients' dopamine levels fell significantly". Hence, a drop in dopamine could cause the sensory structures to be more sensitive, so that normally painless or imperceptible sensory signals from the skin, muscle, blood vessels, and other structure would become more painful (Bailey, 2017). The hypothesis for migraine pain is that pain occurs due to waves or abnormal activity by groups of excitable cells in the brain, these, in turn, can release chemicals or neurotransmitters like serotonin mainly resulting in the narrowing of blood vessels. When serotonin or estrogen levels change in the blood, it results for some as migraine ("How a Migraine Happens - Theories about Migraine Pain," 2020).

The common theory for tension-type headache is that the increase in muscular pain sensation cause increases activation of the spinal cord and brainstem neurons involved in pain signaling as well as activation of neurons in areas of the brain that are involved with processing pain, like the thalamus and somatosensory cortex. This amplified activity causes the pain pathways to become highly sensitized, leading to exaggerated response events to smaller degrees of stimulation. Also, it is found that the mechanism involved with pain inhibition may also begin to fail the suppress pain signaling by compounding the effect (Bendtsen et al., 2010).Headache disorders if left untreated impose a recognizable burden on sufferers that includes impaired quality of life (Terwindt et al., 2003), sleep disorder especially insomnia (Kim et al., 2018), depression, and anxiety (Wei et al., 2016). A study found that subjects with migraine-type headaches were not able to carry out activities and the total loss of workdays per one year is 270 days per 1000 persons. For tension-type headaches, the estimated absenteeism of working days is 820 (Rasmussen et al., 1992). 
Table 1 PICOS and eligibility criterion

\begin{tabular}{|c|c|c|}
\hline PICO & Inclusion Criteria & Exclusion Criteria \\
\hline Patients & $\begin{array}{c}\text { Migraine headache, tension type headache, cluster } \\
\text { headache }\end{array}$ & $\begin{array}{l}\text { Non-human subjects, pregnant women, secondary } \\
\text { headache }\end{array}$ \\
\hline Intervention & Aerobic exercises & $\begin{array}{l}\text { Manual therapy, no intervention including diagnostic or } \\
\text { prevalence studies or secondary headache }\end{array}$ \\
\hline Control & Relaxation exercise, Medications & - \\
\hline Outcome & Pain, Quality of life & - \\
\hline Study design & RCT, Case-Control, Case studies & Non-English, meta-analyses and systematic reviews \\
\hline
\end{tabular}

Table 2 Characteristics of Studies Included and the Outcome Measure

\begin{tabular}{|c|c|c|c|c|c|}
\hline Study & $\begin{array}{l}\text { No. of } \\
\text { subjects }\end{array}$ & $\begin{array}{c}\text { Age } \\
\text { (Mean \& SD) }\end{array}$ & Population & $\begin{array}{l}\text { Design/ } \\
\text { Sampling }\end{array}$ & Outcome measure \\
\hline $\begin{array}{l}\text { Sertel et } \\
\text { al., } 2017\end{array}$ & 60 & $39.26 \pm 9.23$ & $\begin{array}{l}\text { Tension- type } \\
\text { headaches }\end{array}$ & $\begin{array}{c}\text { Block } \\
\text { Randomization }\end{array}$ & $\begin{array}{l}\text { Visual analog scale and pain diary, pain } \\
\text { disability index, headache impact tests and } \\
\text { SF-36. }\end{array}$ \\
\hline $\begin{array}{l}\text { Krøll et al., } \\
\quad 2018\end{array}$ & 52 & 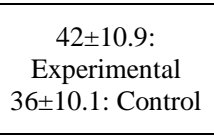 & $\begin{array}{l}\text { Migraine and co- } \\
\text { existing tension- } \\
\text { type headache } \\
\text { and neck pain } \\
\end{array}$ & $\begin{array}{c}\text { Randomized } \\
\text { Controlled Clinical } \\
\text { Trial }\end{array}$ & $\begin{array}{l}\text { Pain frequency, intensity, and duration, } \\
\text { neck pain, physicalfitness, level of physical } \\
\text { activity, well-being. }\end{array}$ \\
\hline $\begin{array}{l}\text { Santiago et } \\
\text { al., } 2014\end{array}$ & 60 & 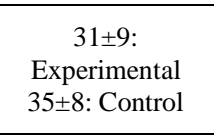 & Chronic Migraine & $\begin{array}{l}\text { Randomized } \\
\text { Controlled Trial }\end{array}$ & $\begin{array}{l}\text { Frequency, intensity and duration, days of } \\
\text { the analgesic medication use, body mass } \\
\text { index, beck depression inventory and beck } \\
\text { anxiety inventory. }\end{array}$ \\
\hline $\begin{array}{l}\text { Varkey et } \\
\text { al., } 2011\end{array}$ & 91 & $44.3 \pm 10.6$ & Migraine & $\begin{array}{c}\text { Randomized } \\
\text { Controlled Trial }\end{array}$ & $\begin{array}{l}\text { Migraine status, quality of life, level of } \\
\text { physical activity and oxygen uptake. }\end{array}$ \\
\hline $\begin{array}{l}\text { Andersen } \\
\text { et al., } 2011\end{array}$ & 198 & $\begin{array}{l}44 \pm 11: 2 \mathrm{~min} \\
\text { group } \\
42 \pm 11: 12 \mathrm{~min} \\
\text { group } \\
43 \pm 10: \text { control } \\
\text { group }\end{array}$ & $\begin{array}{l}\text { Headache } \\
\text { (combined with } \\
\text { migraine and } \\
\text { Tension-type) }\end{array}$ & $\begin{array}{l}\text { Randomized } \\
\text { Controlled Trial }\end{array}$ & $\begin{array}{l}\text { Frequency, intensity, and duration of } \\
\text { headache. }\end{array}$ \\
\hline
\end{tabular}
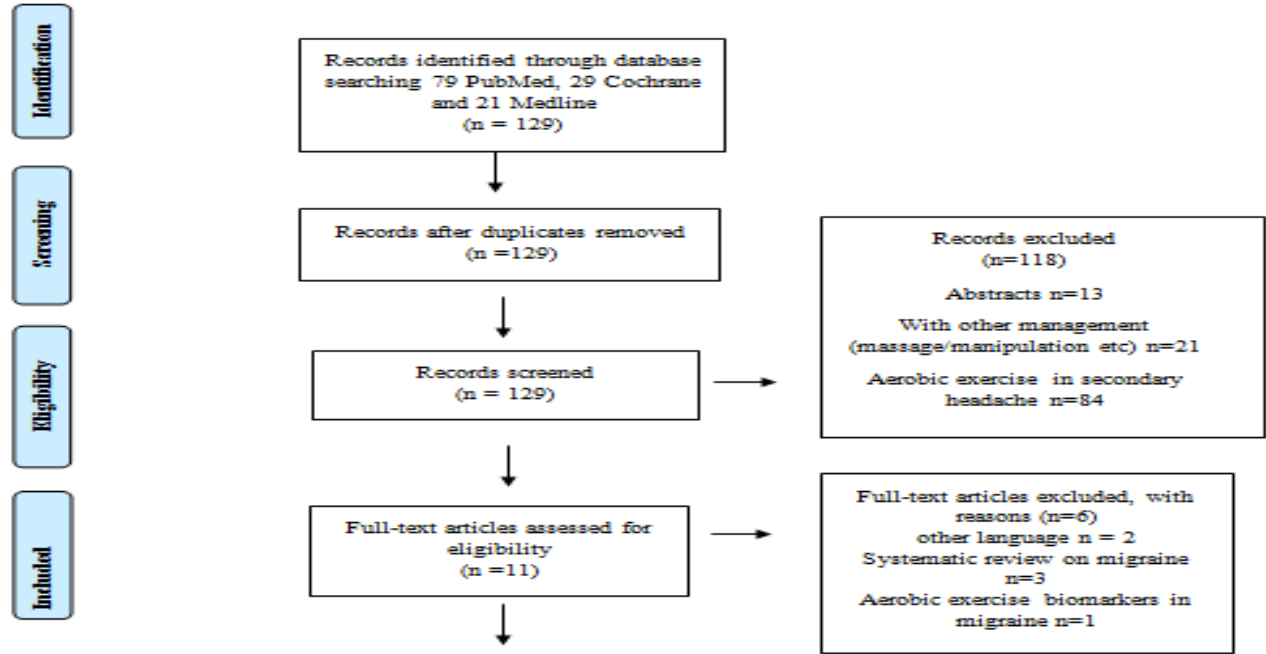

Studies included in qualitative synthesis

Combined Headache: $n=1$

Tension type headaches: $n=1$

Figure 1 Flow Chart of Study Selection

Journal of Experimental Biology and Agricultural Sciences

http://www.jebas.org 
Table 3 Interventions of Experimental and Control Groups with Results of Included Studies

\begin{tabular}{|c|c|c|c|c|}
\hline Study & $\begin{array}{l}\text { Experimental } \\
\text { group }\end{array}$ & $\begin{array}{l}\text { Intervention and Intensity for } \\
\text { experimental group }\end{array}$ & Control group & Results \\
\hline $\begin{array}{l}\text { Sertel et } \\
\text { al., } 2017\end{array}$ & $\begin{array}{l}\text { Group 2: Aerobic } \\
\text { exercise via step- } \\
\text { dance } \\
\text { accompanied by } \\
\text { music }\end{array}$ & $\begin{array}{c}\text { Step-dance training } \\
\text { accompanied by music for } 40 \\
\text { min, } 3 \text { sessions/ week for } 6 \\
\text { weeks with RPE: } 13-14 \text { points. }\end{array}$ & $\begin{array}{l}\text { Group 1:BAT: relaxation, } \\
\text { motion and massage } \\
\text { Group 3: No exercises }\end{array}$ & $\begin{array}{l}\text { BAT and Aerobic Exercise together } \\
\text { can bring about reduction in pain } \\
\text { intensity. }\end{array}$ \\
\hline $\begin{array}{l}\text { Krøll et } \\
\text { al., } 2018\end{array}$ & Aerobic exercise & $\begin{array}{l}\text { Bike/cross-trainer/brisk walking } \\
\text { for } 45 \text { minutes, three times/week } \\
\text { for } 3 \text { months with RPE: } 14-16 \\
\text { points. }\end{array}$ & $\begin{array}{l}\text { Controls continued usual } \\
\text { daily activities }\end{array}$ & $\begin{array}{l}\text { Exercise significantly reduced the } \\
\text { burden of migraine and the ability to } \\
\text { engage in physical activity because of } \\
\text { reduced impact of tension-type } \\
\text { headache and neck pain. }\end{array}$ \\
\hline $\begin{array}{l}\text { Santiago } \\
\text { et al., } \\
2014\end{array}$ & $\begin{array}{l}\text { Aerobic exercise } \\
\text { and amitriptyline }\end{array}$ & $\begin{array}{c}\text { Outdoor fast walking for } 40 \\
\text { minutes with a frequency of } 3 \\
\text { times/week for } 12 \text { consecutive } \\
\text { weeks with Amitriptyline ( } 25 \\
\text { mg/day) }\end{array}$ & Amitriptyline ( $25 \mathrm{mg} /$ day $)$ & $\begin{array}{l}\text { amitriptyline was an effective } \\
\text { treatment for chronic migraine, but its } \\
\text { efficacy was increased when } \\
\text { combined with aerobic exercise. }\end{array}$ \\
\hline $\begin{array}{l}\text { Varkey et } \\
\text { al., } 2011\end{array}$ & Exercise & $\begin{array}{l}\text { Indoor cycling } 40 \mathrm{~min} 3 \\
\text { times/week, for } 3 \text { months with } \\
\text { RPE } 14-16 \text { points. }\end{array}$ & $\begin{array}{l}\text { Relaxation group: breathing, } \\
\text { stress management } 5-20 \\
\text { min. } \\
\text { Topiramate group: } 25 \mathrm{mg} \\
\text { every week till max dosage } \\
\text { to } 200 \mathrm{mg} / \text { day. }\end{array}$ & $\begin{array}{l}\text { Exercise may be an option for the } \\
\text { prophylactic treatment of migraine in } \\
\text { patients who do not benefit from ordo } \\
\text { not want to take daily medication. }\end{array}$ \\
\hline $\begin{array}{l}\text { Andersen } \\
\text { et al., } \\
2011\end{array}$ & $\begin{array}{l}\text { Resistance type of } \\
\text { aerobic training }\end{array}$ & $\begin{array}{l}\text { Resistance training with elastic } \\
\text { tubing at } 2 \mathrm{~min} \text { and } 12 \mathrm{~min} / \text { day, } \\
5 \text { times a week for } 10 \text { weeks. }\end{array}$ & Health related information & $\begin{array}{c}\text { Two minutes of daily resistance } \\
\text { training for ten weeks reduces } \\
\text { headache pain, frequency among } \\
\text { office workers with neck/shoulder } \\
\text { pain. }\end{array}$ \\
\hline
\end{tabular}

Among the conducted studies, $20 \%$ of the study population reported headaches one or more times a week, which was analyzed using the PedMIDAS scale, and the average score is over 12. Further, $10 \%$ of the school children aged between 12-15 years were analyzed for PedMIDAS and found to have a score of 16.8 whereas the PedsQL4 generic quality of life score is about 70.1.These results can indicate even children with headache have a poorer quality of life than compared to that of children with neurological or cardiovascular disorders like asthma, diabetes, or cancer. An average of 0.6 days of school was missed in 3 months across all school children (Kernick et al., 2009). These recognizable burdens are purely due to pain. Hence it is important to consider pain which in turn can affect the quality of life. The treatment for primary headaches is not common; it depends on severity, symptoms, and disability. Though pharmacological medications may be advised, it cannot be given for a longer duration due to its side effects. Thus, a non-pharmacological intervention is required to enhance the quality of life. Exercises can be of different types. It includes stretching, deep breathing and muscle relaxation, yoga, and cardiovascular exercises. Habitual aerobic exercise has a major advantage of preventing or reducing symptoms of several chronic diseases and medical conditions (Irby et al., 2016). Aerobic or cardiovascular exercise by definition is a form of bodily movement that is fuelled by aerobic energy-generating processes, where the energy demands of the exercise performed do not exceed the rate at which the cardiovascular system can supply oxygen to working muscles (McArdle et al., 1980). Aerobic exercises have already been proven to reduce the frequency, duration, severity, or associated disability in migraine (Irby et al., 2016).

When one exercise, the body releases endorphins, which are the body's natural painkillers and natural anti-depressants chemicals called enkephalins. This could mean providing a planned exercise can improve the overall function. According to the Centre of Disease Control and Prevention (CDC), an adult should exercise 150 minutes of moderate-intensity aerobic exercise and 2 or more days a week of muscle-strengthening each week for relief of migraine or primary headaches (Robbins, 2015). According to the American migraine foundation, the exercise program should include cardiorespiratory fitness, flexibility exercises, and muscular strengthening. As most of the studies found that aerobic exercises can reduce frequency, severity, and duration (Varkey et al., 2011; Santiago et al., 2014; Krøll et al., 2018). The purpose of this study is to investigate whether aerobic exercise influences pain and quality of life among subjects with primary headaches and are these studies are based on sufficient data. 
Table 4 Interventions of Experimental and Control Groups with Results on Pain and Quality of Life

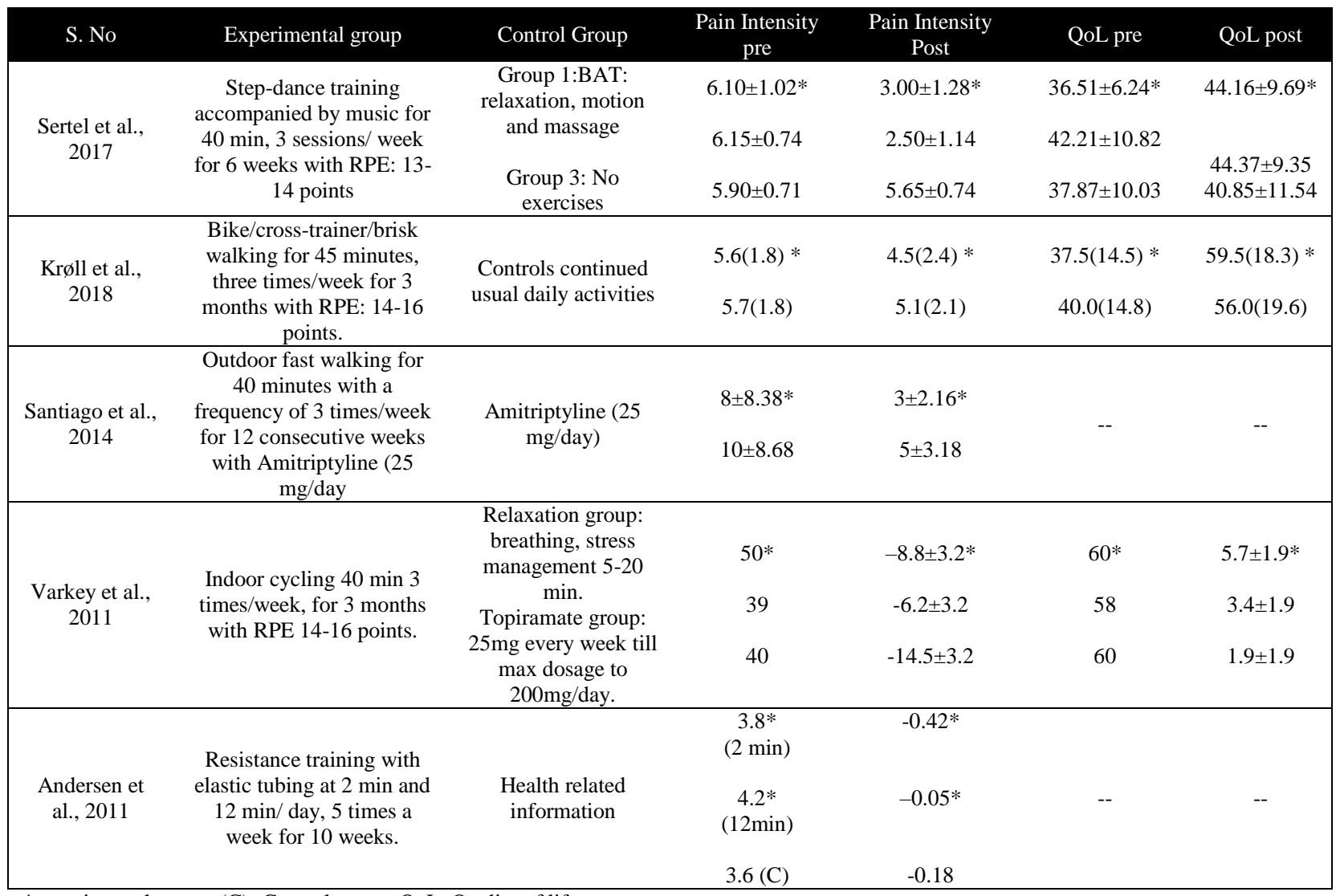

*experimental group, (C)- Control group, QoL: Quality of life

\section{Materials and Methods}

\subsection{Search strategy}

To organize the search strategy, a PICO format was used (Table 1 PICO - Evidence-Based Medicine, 2016). Three electronic databases were analyzed to identify eligible studies: PubMed, Cochrane, and Medline databases from the period of 2010 to February 2020. An additional search of grey literature for this study was not performed. The search terms used were aerobic exercise and tension-type headaches, migraine, cluster headaches, pain, and quality of life. The search strategy identified five articles that considered the effect of aerobic exercise on primary headaches.

\section{Results}

\subsection{Study selection}

The study yielded 79 studies in PubMed, 29 studies in Cochrane, and 21 in Medline concerning primary and secondary headaches. There were no duplications in the articles found. Of the 129 studies, 118 articles were excluded because 13 articles were abstracts though few were on primary headaches, 21 articles had inclusion as massage, manipulation in the intervention so was excluded and 84 articles were on secondary headache like stroke, brain injury, etc.; and only 11 studies were retrieved and screened on full text. After screening on full text, five studies were found eligible and were included in this study (Figure 1).

\subsection{Study characteristics}

The studies included were all RCTs, except for one. Studies included subjects with headaches like migraine, cluster, and tension-type. Of the 5 studies included, one was on combined headache (migraine and tension-type), three on migraine headache, and one on tension-type headaches. A total number of 479 subjects participated in these studies with 198 subjects with headache, 221 with migraine type, and 60 with tensiontype headache. The mean age of all included subjects was 40 years. The average baseline headache duration of tension-type not specified (Sertel et al., 2017), for that of migraine type is 11.7 days (Varkey et al., 2011; Santiago et al., 2014; Krøll et al., 2018) and 5.6\% for combined headache (Andersen et al., 2011). 


\subsection{Synthesis of the results}

For each study, a summary of characteristics of participants, design, intervention, control, and outcome is presented in Table2 (Characteristics of studies included and outcome measure) and Table 3 (Interventions of experimental and control groups with results of included studies).

\subsection{Intervention}

Types of aerobic exercises used in the studies were screened and analyzed. One study used a step-dance board accompanied by music for 30 minutes with 5 minutes of warm-up and cool down. The intensity corresponds to $13-14$ points of 6-20 point BORG scale (Sertel et al., 2017) one a combination of indoor or outdoor bike, cross trainer or brisk walking and exercise with the trained physiotherapist for 30 minutes with 10 minutes of warm-up and 5 minutes of cool down. The intensity corresponds to 14-16 points on the BORG scale (Krøll et al., 2018). Two, outdoor fast walking for 40 minutes (Santiago et al., 2014).

Third, indoor cycling for 20 minutes with 15 minutes of warmup and 5 minutes of cool down. The intensitycorresponds to RPE scale 14-16 (Varkey et al., 2011). Fourth, training with elastic tubing either for 2 minutes or 12 minutes per day without any warm-up or cool down (Andersen et al., 2011). Table 3 summarizes the type and intensity of intervention of all included studies.

\subsection{Control}

All 5 studies had a control group. One study had 2 control groups one with a body awareness therapy (BAT) program that included relaxation, motion, and massage and one without intervention (Sertel et al., 2017). In other studies, patients with migraine included in the control group received no intervention (Krøll et al., 2018), treatment based on medication amitriptyline (Santiago et al., 2014). Further, one study had 2 control groups, among these, one with a relaxation exercise and another one is a treatment based on topiramate medication (Varkey et al., 2011). Other studies had treatment based on health information (Andersen et al., 2011). Table 3 summarizes the interventions of control.

\subsection{Effect of aerobic exercise on Pain Intensity and Quality of Life}

Among the selected five studies, four studies have reported a reduction of pain intensity following aerobic exercise.In all the analyzed studies, only pain intensity was considered whereas the duration and frequency are not studied.
In one of the study, pain intensity as measured by visual analogy scale was reduced from $5.90 \pm 0.71$ to $5.65 \pm 0.74$, and

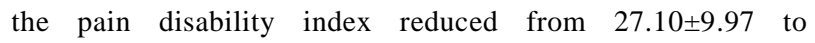
$26.10 \pm 10.39$ compared to control groups (Sertel et al., 2017). In another study following the intervention, the pain intensity reduced from $4.5 \pm 1.4$ to $3.9 \pm 1.8$ (Krøll et al., 2018). With medication amitriptyline as control, the pain intensity in the aerobic exercise group reduced from $10 \pm 8.68$ to $5 \pm 3.18$ (Santiago et al., 2014), with topiramate as one of the control, the pain intensity in experimental as measured by visual analogy scale (point 1-100) reduced from $50 \%$ to $8.8 \pm 3.2$ at last month of treatment (Varkey et al., 2011). In another study, the pain intensity remained unchanged following exercise (Andersen et al., 2011). Of the five studies, only 3 studies have reported about quality of life and its result following aerobic exercise. In a study, quality of life as assessed using SF 36 showed improvement from $36.32 \pm 6.24$ to $44.16 \pm 9.69$ (Sertel et al., 2017), in another study psychological wellbeing improved from $37.5 \pm 14.5$ to $59.5 \pm 18.3$ (Krøll et al., 2018).

In the second study, the quality of life as measured by the migraine-specific quality of life improved from $60 \%$ to $5.7 \pm 1.9$ but the improvement was considerably less when compared to medication (Varkey et al., 2011).

Table 4 summarizes the effect of aerobic exercise on pain and quality of life with pre and post values of tension-type, migraine, and combined headaches (migraine and tensiontype).

In another study, the pain intensity remained unchanged following exercise (Andersen et al., 2011).Of the five studies, only 3 studies have reported about quality of life and its result following aerobic exercise. In a study, quality of life as assessed using SF 36 showed improvement from $36.32 \pm 6.24$ to 44.16 \pm 9.69 (Sertel et al., 2017), in another

In another study, the pain intensity remained unchanged following exercise (Andersen et al., 2011).Of the five studies,

\section{Discussion}

According to the Cleveland clinic, headache resulting in pain may be managed with pharmacological drugs. Medications can be classified into three types: symptomatic relief, which relieves symptoms associated with headache, or abortive therapy that stops the process that causes a headache, or preventive therapy that prevents headache itself. The common and major side effects of these medications are sleepiness, fatigue, nausea, difficulty thinking, dizziness, muscle weakness, and cramps (Boyles, 2003). Due to its greater side effects, a non-pharmacological intervention is required to treat 
the symptoms to prevent the consequences and impairment Hence physical activity and exercise are important to prevent headache disorder symptoms.

This study aimed to analyze the effect of aerobic exercise in subjects with a primary headache on pain intensity and quality of life. From the review, it is clear that only a few articles are available, that is only one study on combined headache (migraine and tension-type), one study on tension-type headache, and three studies on migraine-type headaches. Though the inclusion criteria were primary headaches and their subtypes, it ensured a homogenous group but on the other hand, the control groups were not homogenous because studies control had medication like amitriptyline (Santiago et al. 2014), topiramate (Varkey et al., 2011) and few had relaxation exercises like massage (Sertel et al., 2017), breathing exercise (Varkey et al., 2011) as control.

Based on the available literature review, there is moderate evidence that aerobic exercise can decrease pain intensity and low-level evidence that it can improve quality of life. This result is similar to the conclusion of Daenen et al.(2015). The moderate to low-level evidence could be due to a smaller number of studies. Aerobic exercise protocol as analyzed includes step-dance board (Sertel et al., 2017), a combination of indoor or outdoor bike, cross trainer or brisk walking (Krøll et al., 2018), outdoor fast walking (Santiago et al., 2014), indoor cycling (Varkey et al., 2011) and resistance training with elastic tubing (Andersen et al., 2011), indicates that there is no specific protocol being established.

The moderate to the low level of evidence may also be due to dropouts in the studies. The reasons for dropouts both in the experimental and control group being transportation difficulty (Sertel et al., 2017), family issues (Sertel et al., 2017), lack of time and energy, no explanation (Varkey et al., 2011; Sertel et al., 2017), pregnancy (Sertel et al., 2017), illness (Sertel et al., 2017), pain following test (Sertel et al., 2017), dissatisfied with treatment (Varkey et al., 2011; Sertel et al., 2017), started other treatment (Krøll et al., 2018), side effects due to drugs (Santiago et al., 2014; Varkey et al., 2011), noncompliance (Varkey et al., 2011), lost follow-up (Andersen et al., 2011). Most of these studies had 3 months (Varkey et al., 2011; Santiago et al., 2014; Sertel et al., 2017; Krøll et al., 2018), as well as 6 months (Varkey et al., 2011; Sertel et al., 2017; Krøll et al., 2018), follow up.

Cluster headaches on the other side were not studied for aerobic exercises. This could be because the most well-known treatment is $100 \%$ oxygen therapy. This technique is considered a level A recommendation and is unique to cluster headaches. The nil evidence for aerobic exercise can be because around $25 \%$ of patients who experiences cluster headache will never have another one. This condition as such can resolve in 15 years (Kandel \& Mandiga, 2020). But these patients if left undiagnosed can experience detriments in their mental health, physical burdens, and loss of quality of life. It is also found many patients have suicidal ideation (Hoffman \& May, 2018). Hence further studies are needed to check whether aerobic exercise can alter or resolve symptoms and reduce cognitive issues. Large population-based studies following experimental analyses concluded that if the physical activity is reduced or less, it is more often associated with higher or increased prevalence and frequency of migraine and other headaches (Queiro et al., 2009). Adolescent men with lower cardiovascular fitness are estimated to be at higher risk of developing prescription pharmacological drugs for migraine symptoms (Nyberg et al., 2019). Although participation in regular exercise is routinely recommended as a means of managing and preventing headache, the pieces of evidence for this recommendation or specific protocol to prescribe aerobic exercise is well less defined.

The regular practice of aerobic exercise seems to benefit patients with headache. These benefits could be majorly due to changes in nitric oxide levels (Narin et al., 2003), increased production of beta-endorphins especially in migraineurs headaches (Koseoglu et al., 2003), but these controlled studies do not define the optimal frequency and intensity of exercise. Despite the positive results for decreased pain, frequency, duration, frequency, and improvement in the quality of life, there are only a few studies about the real influence of aerobic type exercise on other clinical consequences of headache.Though it is well known that primary headache either combined or isolated subtypes are all neurovascular, neuroinflammatory disorders, beyond neurological and physiological pathways, improvements in aerobic fitness and symptoms are associated with overlapping changes in psychological, behavioral, and socio-cognitive factors which must be considered. It is important both for clinical and a public health perspective to identify brain activity, hormone levels over time for future considerations.

\section{Conclusion}

The availability of data on the importance and impact of aerobic exercise on pain and quality of life in primary headaches though is limited, further research is needed to estimate the definitive protocol. From these evidences, we can conclude that aerobic exercises are the best option for reducing pain and improving quality of life in primary headaches, especially for tension-type and migraine-type headaches.

Conflict of Interest: No conflicts exist. 


\section{References}

Ahmed F (2012) Headache disorders: differentiating and managing the common subtypes. British Journal of Pain 6(3): 124-132. https://doi.org/10.1177/2049463712459691.

Andersen L L, Mortensen $\mathrm{O}$ S, Zebis M K, Jensen R H, Poulsen O M (2011) Effect of brief daily exercise on headache among adults - Secondary analysis of a randomized controlled trial. Scandinavian Journal of Work, Environment and Health 37(6): 547-550. https://doi.org/10.5271/sjweh.3170.

Bailey L (2017) Brain scans show dopamine levels fall during migraine attacks. Michigan News. University of Michigan. Availabl at https://news.umich.edu/brain-scans-showdopamine-levels-fall-during-migraine-attacks/ access on 25th October 2019.

Bendtsen L, Fumal A, Schoenen J (2010) Tension-type headache: mechanisms. Handbook of Clinical Neurology 97: 359-366. https://doi.org/10.1016/S0072-9752(10)97029-2.

Boyles S (2003) Migraine drugs effects scare many away. WebMD. https://doi.org/10.1136/bmj.c4999.

Carbaat P A T, Couturier E G M (2016) Headache: classification and diagnosis. Nederlands Tijdschrift Voor Tandheelkunde 123(11): 539-544 https://doi.org/10.5177/ntvt.2016.11.16122.

Clinch C R (2001) Evaluation of Acute Headaches in Adults. American Family Physician 63(4): 685-693.

Daenen L, Varkey E, Kellmann M, Nijs J (2015) Exercise, not to exercise, or how to exercise in patients with chronic pain? Applying science to practice.Clinical Journal of Pain 31(2): 108-114. https://doi.org/10.1097/AJP.0000000000000099.

Koseoglu E, Akboyraz A, Soyuer A, Ersoy AO (2003) Aerobic exercise and plasma beta endorphin levels in patients with migrainous headache without aura. Cephalalgia 23(1): 972976. https://doi.org/10.1046/j.1468-2982.2003.00624.x.

Hagen K, Åsberg A N, Uhlig B L, Tronvik E, Brenner E, Stjern M, Helde G, Gravdahl G B, Sand T (2018) The epidemiology of headache disorders: a face-to-face interview of participants in HUNT4. Journal of Headache and Pain 19(1): 2-7. https://doi.org/10.1186/s10194-018-0854-2.

Hoffman J, May A (2018) Diagnosis, pathophysiology, and management of cluster headache. The Lancet Neurology 17(1): 75-83. https://doi.org/10.1016/S1474-4422(17)30405-2.
How a Migraine Happens: Theories about migraine pain (2020). The Johns Hopkins University. Available at http://www.hopkinsmedicine.org/healthlibrary/conditions/nerv ous_system_disorders/how_a_migraine_happens_85,P00787/ access on 25th October 2020.

Irby M B, Bond D S, Lipton R B, Nicklas B, Houle T T, Penzien D B (2016) Aerobic Exercise for Reducing Migraine Burden: Mechanisms, Markers, and Models of Change Processes. Headache 56(2): 357-369. https://doi.org/doi:10.1111/head.12738.

Jensen R, Stovner L J (2008) Epidemiology and comorbidity of headache. The Lancet Neurology 7(4): 354-361. https://doi.org/10.1016/S1474-4422(08)70062-0.

Kandel S A, Mandiga P (2020) Cluster Headache. StatPearls [Internet]. https://www.ncbi.nlm.nih.gov/books/NBK544241.

Kernick D, Reinhold D, Campbell J L (2009) Impact of headache on young people in a school population. British Journal of General Practice 59(566): 678-681. https://doi.org/10.3399/bjgp09X454142.

Kim S J, Han K T, Jang S Y, Yoo K B, Kim S J (2018) The association between migraine and types of sleep disorder. International Journal of Environmental Research and Public Health 15(12). https://doi.org/10.3390/ijerph15122648.

Krøll L S, Hammarlund C S, Linde M, Gard, Jensen R H (2018) The effects of aerobic exercise for persons with migraine and co-existing tension-type headache and neck pain. A randomized, controlled, clinical trial. Cephalalgia 38(12): 1805-1816. https://doi.org/10.1177/0333102417752119.

McArdle W D, Katch F I, Katch V L (1980) Nutrition, energy, and human performance. Exercise physiology (p. Chapter 21).

Narin S O, Pinar L, Erbas D, Ozturk V, Idiman F (2003) The effects of exercise and exercise-related changes in blood nitric oxide level on migraine headache. Clinical Rehabilitation 17(6): 624-630. https://doi.org/doi: 10.1191/0269215503cr657oa.

Nyberg J, Gustavsson S, Linde M, Aberg N D, Rohmann J L, Aberg M, Kurth T, Waern M, Kuhn G H (2019) Cardiovascular fitness and risk of migraine: a large, prospective populationbased study of Swedish young adult men. BMJ Open 9(8): 1-9. https://doi.org/10.1136/bmjopen-2019-029147.

PICO - Evidence Based Medicine (2016) The Board of Trustees of the University of Illinois. Available at 
https://researchguides.uic.edu/ebm access on 25th October 2019.

Primary headache disorders: Types (2019) In Internationalheadache society. Available at https://ichd-3.org access on 25th May 2020.

Queiroz LP, Peres MF, Piovesan EJ, Kowacs F, Ciciarelli MC, Souza JA, Zukerman E (2009) A nationwide population-based study of migraine in Brazil. Cephalalgia 29(6): 642-649. https://doi.org/10.1111/j.1468-2982.2008.01782.x.

Rasmussen BK, Jensen R, Olesen J (1992) Impact of headache on sickness absence and utilisation of medical services: a Danish population study. Journal of Epidemiology and Community Health 46(4): 443-446. https://doi.org/10.1136/jech.46.4.443.

Robbins L (2015) Exercise Tips for Migraines and Headaches. Practical Pain Management. Available at https://www.practicalpainmanagement.com access on 25th May 2020 .

Santiago M D S, Carvalho D de S, Gabbai A A, Pinto M M pereira, Moutran A R C, Villa T R (2014) Amitriptyline and aerobic exercise or amitriptyline alone in the treatment of chronic migraine: a randomized comparative study. Arquivos de Neuro-Psiquiatria72(11): 851-855 https://doi.org/10.1590/0004-282X20140148.

Sertel M, Bakar Y, Şimşek T T (2017) the Effect of Body Awareness Therapy and Aerobic Exercises on Pain and Quality of Life in the Patients With Tension Type Headache. African Journal of Traditional, Complementary, and Alternative Medicines : $\quad$ AJTCAM $\quad 14(2)$ : $\quad 288-310$.

https://doi.org/10.21010/ajtcam.v14i2.31.

Stovner L J, Hagen K, Jensen R H, Katsarava Z (2007) The Global Burden of Headache: A Documentation of Headache Prevalence and Disability Worldwide. Cephalalgia 27(3): 193210. https://doi.org/10.1111/j.1468-2982.2007.01288.x.

Terwindt G M, Ferrari M D, Launer L J (2003) The impact of headache on quality of life. Journal of Headache and Pain 4(SUPPL. 1): 35-41. https://doi.org/10.1007/s101940300007.

Varkey E., Cider Å, Carlsson J, Linde M (2011) Exercise as migraine prophylaxis: A randomized study using relaxation and topiramate as controls. Cephalalgia 31(14): 1428-1438. https://doi.org/10.1177/0333102411419681.

Wei CB, Jia JP, Wang F, Zhou AH, Zuo XM, Chu CB (2016) Overlap between Headache, Depression, and Anxiety in General Neurological Clinics: A Cross-sectional Study. Chinese Medical Journal 129(12): 1394-1399. https://doi.org/10.4103/0366-6999.183410.

Wei DYT, Ong J J Y, Goadsby P J (2018) Cluster headache: Epidemiology, pathophysiology, clinical features, and diagnosis. Annals of Indian Academy of Neurology 21(5): S3S8.https://doi.org/10.4103/aian.AIAN_349_17.

Yancey J R, Sheridan R, Koren K G (2014) Chronic daily headache: diagnosis and management. American Family Physician 89(8): 642-648. 